\title{
Preparation of Poly(amide-imide)-silica Hybrid Materials by Sol-gel Process
}

\author{
Atsushi Morikawa $^{1}$, Kazunori Suzuki ${ }^{2}$, and Kenji Asano ${ }^{2}$ \\ ${ }^{1}$ Department of Biomolecular Functional Engineering, Ibaraki University, Hitachi, \\ Ibaraki 316-8511, Japan \\ ${ }^{2}$ Power System Laboratory, Hitachi Cable, Ltd., Hitach, Ibaraki 319-1411, Japan
}

\begin{abstract}
Poly(amide-imide)-silica hybrid films were prepared using the sol-gel process of tetraethoxysilane (TEOS). A dianhydride-terminated poly(amide-imide) oligomer was prepared by the reaction of 4,4-diphenylmethanediisocyanate (MDI) and trimellitic andydride (TMA) (MDI:TMA $=2: 3$ equivalents) in $N$-methylpyrrolidone (NMP) at $120{ }^{\circ} \mathrm{C}$. One equivalent of 4,4'-diaminodiphenylmethane (DADPM) was added to the oligomer solution at room temperature to form the poly(amide-imide) precursor having carboxylic acid groups. The hydrolysis-polycondensation of TEOS could be carried out in the solution, and the poly(amide-imide)-silica hybrid film was obtained by casting the homogeneous silica-containing solution onto a glass plate, followed by heating at $300{ }^{\circ} \mathrm{C}$. The silica content was $33 \mathrm{wt} \%$, and silica particles with diameter of about $2 \mu \mathrm{m}$ were observed in the hybrid films by scanning electron microscopy (SEM).

Keywords: sol-gel process, poly(amide-imide)-silica hybrid, 4,4'-diphenylmethanediisocyanate, trimellitic andydride, 4,4'-diaminodiphenylmethane, tetraethoxysilane
\end{abstract}

\section{Introduction}

The sol-gel process is a method for preparation of inorganic metal oxides starting from organic metal alkoxides. The reaction consists of hydrolysis of the metal alkoxides, followed by polycondensation of the hydrolyzed intermediates. The sol-gel process has been applied in a polymer matrix to prepare inorganic and organic hybrid materials [1]. Polyimide-silica hybrid films have been successfully prepared by the sol-gel reaction of TEOS in polyamic acid solution, with subsequent heating of the resulting film at $270{ }^{\circ} \mathrm{C}$. The hybrid film exhibited a higher modulus, lower coefficient of thermal expansion, and higher10 $\mathrm{wt} \%$ loss temperature than non-hybrid films [2].

We produced enameled wire having a polyimide-silica hybrid insulation layer prepared by the sol-gel process of TEOS $[3,4]$. TEOS was hydrolyzed and then polycondensed in a Kapton-type polyamic acid varnish, which is NMP solution, and the conductor was coated with the silica-containing polyamic acid varnish and then passed through an oven at $260-360{ }^{\circ} \mathrm{C}$ for solvent evaporation and imidation. Since the solvent was evaporated very fast, the silica phase was very small, diameter of about $50 \mathrm{~nm}$. The enameled wire showed higher breakdown voltage than that without silica after thermal deterioration at $300{ }^{\circ} \mathrm{C}$ or $400{ }^{\circ} \mathrm{C}$ due to the small silica particle, and higher thermal resistance.

The purpose of the present work is to produce poly(amide-imide)-silica hybrid insulation enameled wire, which has higher thermal resistance than poly(amide-imide) insulation enameled wire without silica. Poly(amide-imide) is a heat-resistant resin and is used industrially for its outstanding electrical properties and mechanical characteristics as an engineering plastic. Thus, poly(amide-imide) has good processability and its synthesis is relatively easy [5], and poly(amide-imide) insulation enameled wire is produced as well as polyimide. 
Poly(amide-imide) insulation enameled wire heat-resistant next to polyimide insulation enameled wire in the enameled wires having organic polymer insulation layer. The poly(amide-imide) varnish for the enameled wire are easily prepared from TMA and MDI in NMP, and poly(amide-imide) insulation enameled wire are much more economically produced than polyimide insulation enameled wire due to low cost of TMA and MDI. We begin to examine the preparation of poly(amide-imide)-silica hybrid solution by the sol-gel reaction of TEOS in the poly(amide-imide) solution.

\section{Experimental}

\subsection{Materials}

Poly(amide-imide) varnish was purchased from Hitachi Chemical. TMA, MDI, DADPM and TEOS were purchased from Wako Pure Chemical Industry. NMP was purchased from Kanto Kagaku Co., Japan, and distilled under reduced pressure over calcium hydride.

\subsection{Sol-gel reaction of TEOS in} poly(amide-imide) varnish

$10.58 \mathrm{~g}(51 \mathrm{mmol})$ of TEOS and $2 \mathrm{~mL}(111$ mmol) of water were added to the poly(amide-imide) varnish, which was a solution of $20 \mathrm{wt} \%$ poly(amide-imide) in NMP, and stirred. The heterogeneous silica-containing poly(amide-imide) varnish formed a gel after stirring for about 7 days.

\subsection{Preparation of poly(amide-imide) precursor} having carboxylic acid groups

To a flask equipped with a condenser, $3.337 \mathrm{~g}$ (13.3 mmol) of MDI, $3.842 \mathrm{~g}$ (20 mmol) of TMA and $30 \mathrm{~mL}$ of NMP were added. The mixture was stirred at $120{ }^{\circ} \mathrm{C}$ for $12 \mathrm{~h}$ under a nitrogen atmosphere. The resulting solution was cooled to room temperature. After $1.322 \mathrm{~g}(6.7 \mathrm{mmol})$ of DADPM was added to the solution, the mixture was stirred at room temperature for $12 \mathrm{~h}$ under a nitrogen atmosphere to form a viscous solution. The inherent viscosity was $0.74 \mathrm{dL} \mathrm{g}^{-1}$.

\subsection{Preparation of poly(amide-imide)-silica hybrid} film

$10.58 \mathrm{~g}(51 \mathrm{mmol})$ of TEOS and $2 \mathrm{~mL}$ of water were added to the solution mentioned above. The heterogeneous mixture was stirred for $72 \mathrm{~h}$ until the mixture became homogeneous. Part of the homogeneous NMP solution was cast onto a glass plate. After the cast film had been dried at $80{ }^{\circ} \mathrm{C}$, the poly(amide-imide)-silica hybrid film was obtained by successive heating at $80{ }^{\circ} \mathrm{C}$ for $30 \mathrm{~min}$, $200{ }^{\circ} \mathrm{C}$ for $200 \mathrm{~min}$ and finally $300{ }^{\circ} \mathrm{C}$ for $5 \mathrm{~min}$ under nitrogen. The rest of the NMP solution was stored at $10^{\circ} \mathrm{C}$. The IR spectrum (film) exhibited absorption bands at $1780 \mathrm{~cm}^{-1}, 1720 \mathrm{~cm}^{-1}$ (imide $\mathrm{C}=\mathrm{O}$ ), $1660 \mathrm{~cm}^{-1}$ (amide $\mathrm{C}=\mathrm{O}$ ), $1360 \mathrm{~cm}^{-1}$ (imide $\mathrm{C}-\mathrm{N})$ and $1100 \mathrm{~cm}^{-1}(\mathrm{Si}-\mathrm{O})$.

\section{Results and Discussion}

Poly(amide-imide) is synthesized by the solution polycondensation of DADPM with 4-chloroformylphthalic anhydride via poly(amide-amic acid) [6], as shown in eq 1, or the solution polycondensation of MDI with TMA [5,7], as shown in eq 2. The insulation layer for enameled wire was thus prepared from poly(amide-imide) varnish by solution polycondensation of MDI with TMA, without generating hydrogen chloride, which causes enameled wire to deteriorate.
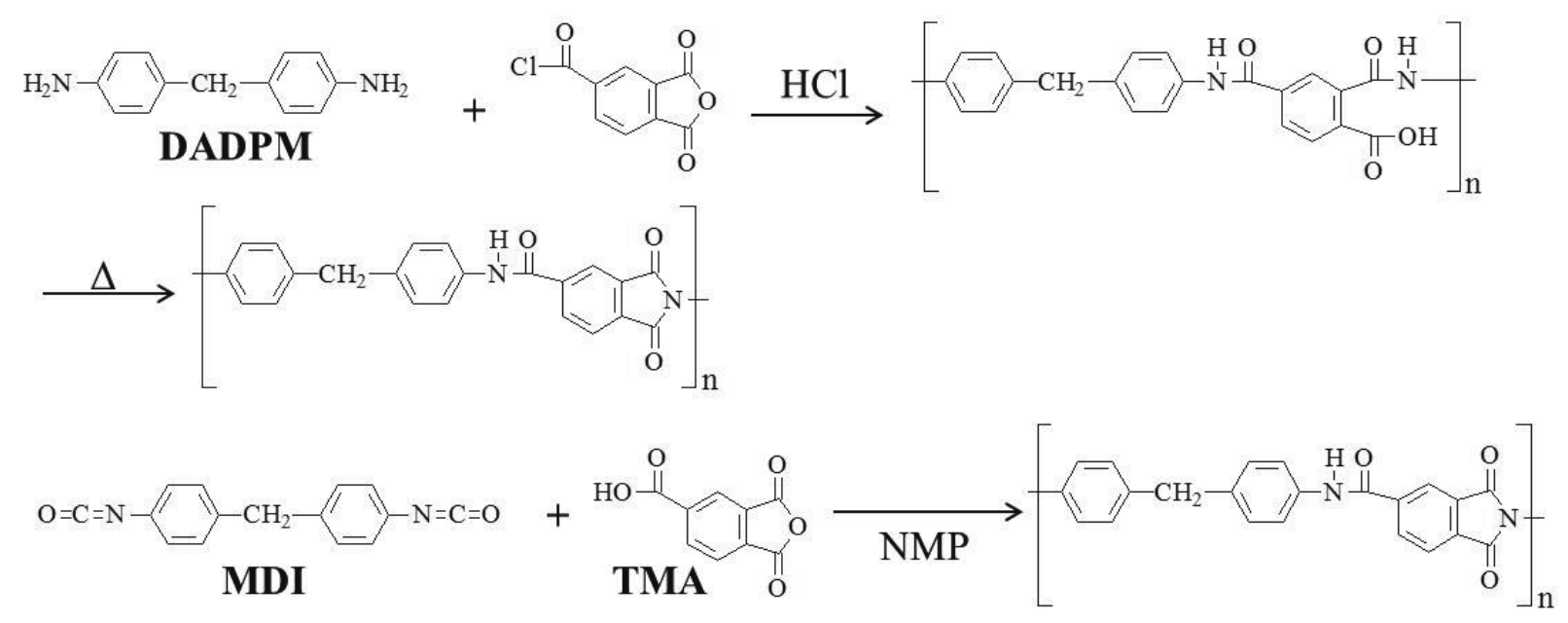
TEOS was reacted with water in the varnish, which was a solution of $20 \mathrm{wt} \%$ poly(amide-imide) in NMP. The heterogeneous silica-containing varnish must be stirred until it becomes homogeneous. While polyamic acid-silica vanish was homogeneous after stirring for about $6 \mathrm{~h}$ in the preparation of polyimide-silica enameled wire, ${ }^{3,4}$ the poly(amide-imide)-silica varnish was not homogeneous in the preparation of poly(amide-imide)-silica enameled wire. The heterogeneous silica-containing poly(amide-imide) varnish formed a gel after stirring for about 7 days. Silica was thought to be stabilized in the polyamic acid vanish due to hydrogen bonds between the silanol groups on the silica surface and the carboxylic acid groups of the polyamic acid. We prepared the poly(amide-imide) precursor having carboxylic acid groups varnish without 4-chloroformylphthalic anhydride by a two-step procedure (Scheme 1). In the first step, poly(amide-imide) oligomers were prepared by the reaction of MDI with a calculated excess of TMA in NMP at $120^{\circ} \mathrm{C}$. In the second step, DADPM was added to the solution after it had been cooled to room temperature, to react with the oligomers. In the first step, if the isocyanate group reacts faster with the carboxyl group than the dicarboxylic anhydride group, a dianhydride-terminated poly(amide-imide) oligomer would be prepared in the first step and DADPM would then react with the oligomer to form a high molecular weight poly(amide-imide) precursor having carboxylic acid groups in the second step. A high molecular weight poly(amide-imide) precursor could not be obtained using 1 equivalent of MDI, 2 equivalents of TMA, and 1 equivalent of DADPM $(\mathrm{m}=0)$, but could be obtained using 2 equivalents of MDI, 3 equivalents of TMA, and 1 equivalent of DADPM $(\mathrm{m}=1)$. The inherent viscosity of the poly(amide-imide) oligomer from TMA and MDI in the first step was 0.15 in NMP, and that of the poly(amide-imide) precursor in the next step was 0.74. The dianhydride-terminated poly(amide-imide) oligomer was thought to be predominantly obtained from MDI and TMA in the first step, and the reaction of the poly(amide-imide) oligomer with DADPM progressed in an equimolar fashion to form the high molecular weight poly(amide-imide) precursor having carboxylic acid groups in the second step.

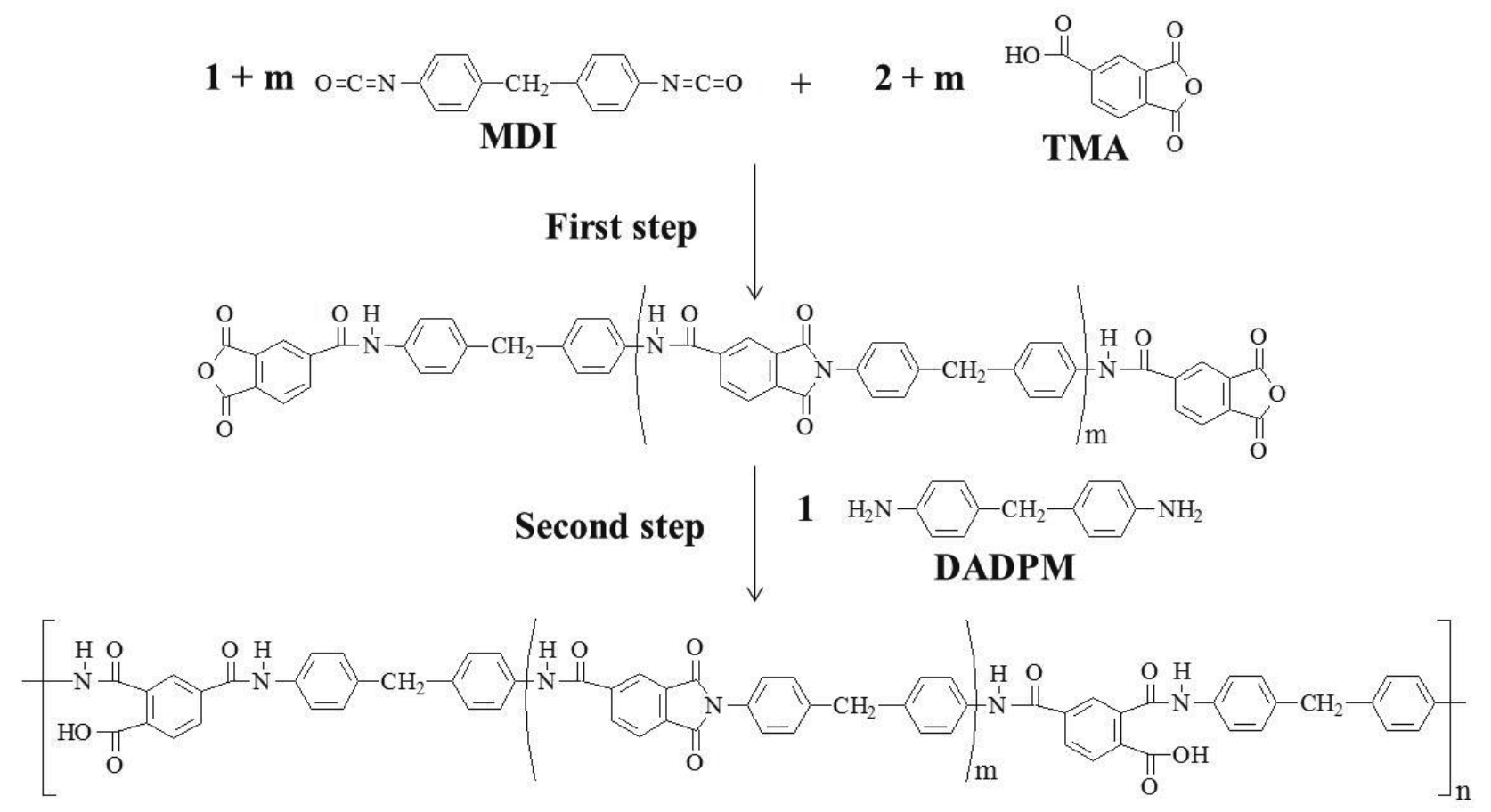

Scheme 1. Preparation of poly(amide-imide) by two-pot procedure 
Preparation of the poly(amide-imide)-silica hybrid varnish was examined by the sol-gel reaction of TEOS. TEOS and water were added to the poly(amide-imide) precursor solution, and the mixture was stirred. A homogeneous silica-containing poly(amide-imide) precursor solution was obtained after stirring for $72 \mathrm{~h}$. A longer time was required to obtain homogeneity than in the case of the polyamic acid varnish due to the smaller percentage of carboxylic acid groups. The NMP solution was cast onto a glass plate to prepare the poly(amide-imide) precursor-silica hybrid film. After the cast film was dried at $80{ }^{\circ} \mathrm{C}$ to evaporate the solvents as well as to develop the siloxane network of silica, thermal cyclodehydration was performed by successive heating at $80{ }^{\circ} \mathrm{C}$ for $30 \mathrm{~min}, 200{ }^{\circ} \mathrm{C}$ for $200 \mathrm{~min}$ and finally $300{ }^{\circ} \mathrm{C}$ for 5 min under nitrogen to form the poly(amide-imide)-silica hybrid film having a silica content of $33 \mathrm{wt} \%$. The chemical structure was confirmed by the appearance of peaks at $1780 \mathrm{~cm}^{-1}$ and $1720 \mathrm{~cm}^{-1}$ (imide carbonyl), $1360 \mathrm{~cm}^{-1}$ (imide C-N), and $1660 \mathrm{~cm}^{-1}$ (amide carbonyl) in the IR spectrum. In addition, the appearance of an absorption at $1100 \mathrm{~cm}^{-1}$ indicated the formation of silicon-oxygen bonds. It was suggested that enameled wire having a poly(amide-imide)-silica hybrid insulation layer could be prepared by the sol-gel process of TEOS. However, the homogeneous silica-containing poly(amide-imide) precursor solution was unstable, and the silica phase separated and formed a heterogeneous gel after standing for about 20 days, whereas phase separation and gelation did not occur in the polyamic acid-silica varnish.

The silica phase in the hybrid films was observed by SEM. Since the silica phase could not be clearly seen in the film, the film was heated at $800{ }^{\circ} \mathrm{C}$ in air to thermally decompose the poly(amide-imide) phase, and the residual silica was observed by SEM. The morphology of the silica in the hybrid film was found to be retained after oxidation at $800{ }^{\circ} \mathrm{C}[3,8]$. Figure 1 shows a SEM photograph of the hybrid film. The dispersed silica particles could be seen as white beads having a diameter of about $2 \mu \mathrm{m}$. The particle size was slightly larger than that in the polyimide-silica (34 $\mathrm{wt} \%$ ) hybrid film prepared by heating at $270{ }^{\circ} \mathrm{C}$ for $3 \mathrm{~h}$ after drying polyamic acid-silica varnish at $80^{\circ} \mathrm{C} .{ }^{4}$

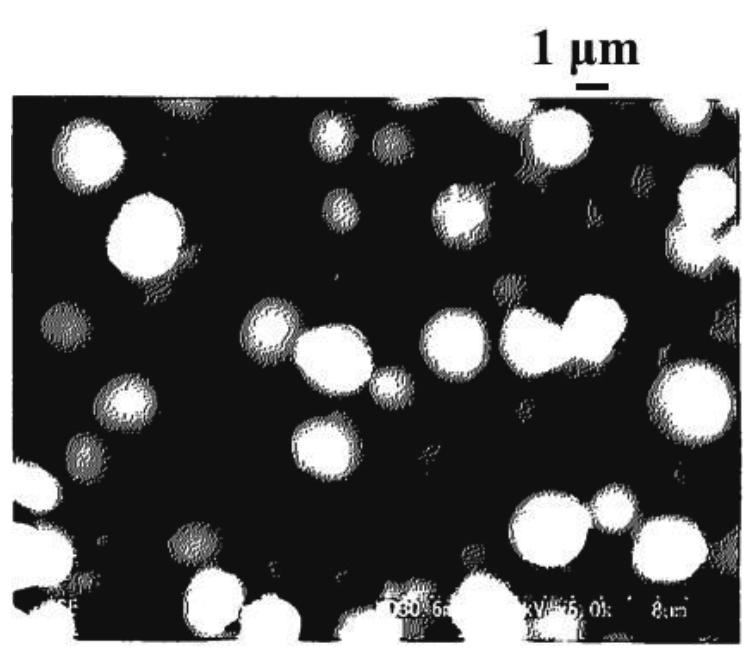

Figure 1. SEM photograph of poly(amide-imide)-silica hybrid film with $33 \mathrm{wt} \%$ silica.

Figure 2 shows typical thermogravimetric curves of the poly(amide-imide)-silica hybrid film and poly(amide-imide) film without silica, which was prepared from the poly(amide-imide) varnish. The decomposition temperature of the poly(amide-imide)-silica hybrid film was as high as that of the poly(amide-imide) film, and imidation proceeded completely. The weight of the residues at $800{ }^{\circ} \mathrm{C}$ was in agreement with the value calculated by assuming that the sol-gel reaction proceeded to completion.

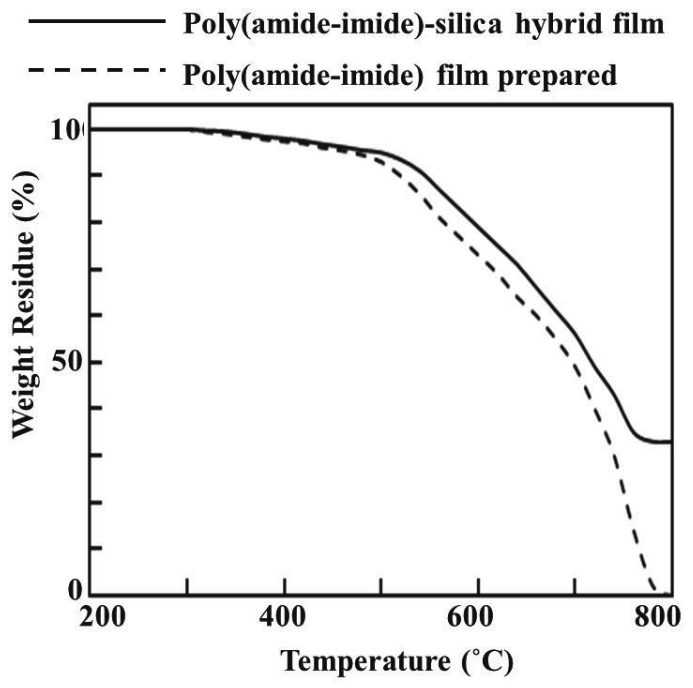

Figure 2. TG curves of poly(amide-imide)-silica hybrid film and poly(amide-imide) film prepared from the varnish. 
Dynamic mechanical behaviors of the poly(amide-imide)-silica hybrid film and poly(amide-imide) film are shown in Figure 3. The poly(amide-imide)-silica hybrid film exhibited a higher value of storage modulus. The glass transition temperature determined by the peak temperature of the $\tan \delta$ curve was $270^{\circ} \mathrm{C}$, slightly higher than that of the poly(amide-imide) film.

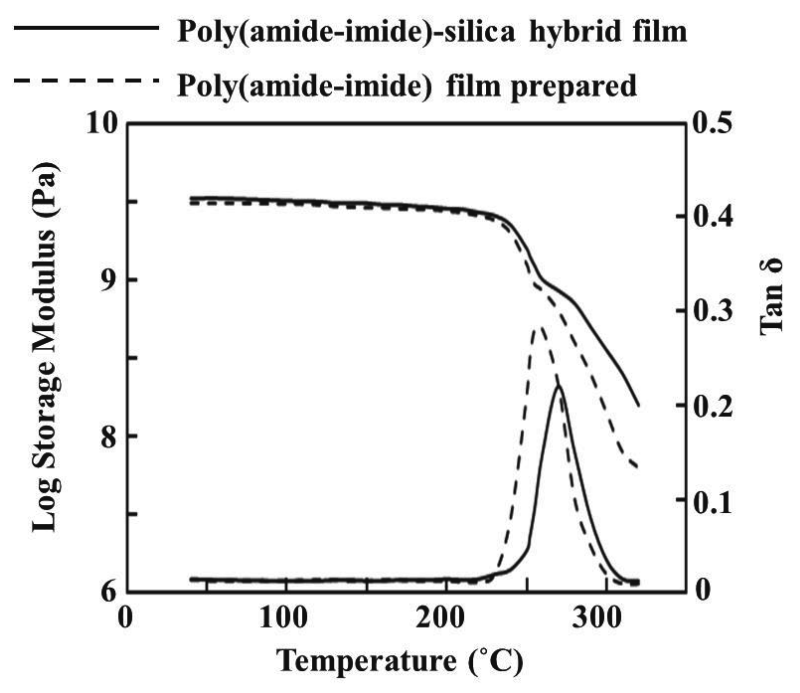

Figure 3. Dynamic mechanical behaviors of poly(amide-imide)-silica hybrid film and poly(amide-imide) film.

\section{Conclusion}

A dianhydride-terminated poly (amide-imide) oligomer was prepared by the reaction of 4,4-diphenylmethanediisocyanate (MDI) and trimellitic andydride (TMA) (MDI: TMA $=2: 3$ equivalents) in NMP at $120{ }^{\circ} \mathrm{C}$. One equivalent of 4,4'-diaminodiphenylmethane (DADPM) was then added to the oligomer solution at room temperature to form the poly(amide-imide) precursor having carboxylic acid groups. The hydrolysis-polycondensation of TEOS was carried out in the solution, and a poly (amide-imide)-silica hybrid film was obtained by casting the homogeneous silica-containing solution on to a glass plate, followed by heating at $300{ }^{\circ} \mathrm{C}$. It was demonstrated that enameled wire having a poly(amide-imide)-silica hybrid insulation layer could be prepared by the sol-gel method.

\section{References}

1. L. L. Hench, K. West, Chem. Rev., 90 (1990) 33-72.

2. Y. Imai and H. Uchiyama, J. Polym. Sci., Part B, Polym. Lett., 8 (1970) 559-562.

3. A. Morikawa, K. Suzuki, and K. Asano, JP-A-Hei-10-289622 (1998).

4. A. Morikawa, K. Suzuki, and K. Asano, J. Photopolym. Sci. Technol., 28 (2015) 151-155.

5. S. Terney, J. Keating, J. Zielinski, J. Hakala, H. Sheffer, J. Polym. Sci., part A, Polym. Chem., 8 (1970) 683-692.

6. W. M. Alvino, J. Appl. Polym. Sci., 19 (1975) 651-663.

7. H. E. Sheffer and G. C. Zielunski, U. S. Pat. 3518230 (1970).

8. A. Morikawa, H. Yamaguchi, M. Kakimoto, and Y. Imai, Chem. Mater., 6 (1994) 913-917. 